\title{
Caderno de Formação 2020
}

Ana Tereza Prado Lopes', Aline Beatriz Seixas de Souza", Amanda Campos Barbosa'l', Amanda Rezende de França Pizani DomicianoIv, Ana Clara Portela Schubert”, Bárbara Carneiro Drummond Alves ${ }^{\mathrm{VI}}$, Beatriz Sampaio lacillo de Albuquerquevil, Bruna Moraes de Araujovill, Carolina Marques Garcia Fernandes Pereira ${ }^{\mathrm{IX}}$, Clara Guaracy MayallX, Ellysson Vicentte Sousa Rocha ${ }^{\mathrm{XI}}$, Érica Castello CastilhoxII, Gabriela Borges de Oliveira LeãoxIII, Guilherme Lemos de AzevedoxIv, Isabella de Oliveira EI Biranixv, Judy Bonfim Velasquez XVI, Julia Barros NogueiraxVII, Luiz Arthur Bittencourt RibeiroxvII, Mariana Pêgas CostaxIx, Maria Clara Soares Monteiro de Barros $\mathrm{xx}$, Maria Helena Paula Motta Gomes XxI, Monique dos Santos Pereira DurandxxII, Naima Bibas Silva VieiraxXIII, Racquel Crespo Fontenele ${ }^{\mathrm{XXI}}$, Renata Rodrigues ${ }^{\mathrm{XXV}}$, Sergio Mauricio Teixeira ${ }^{\mathrm{XXV}}$, Sofia S. de Souza e Silva ${ }^{x x v I I}$, Victória Lopes de Carvalho ${ }^{x x v I I}$.

Resumo: Este caderno tem o objetivo de reunir os resumos das monografias apresentadas pelos alunes do lart no ano letivo de 2020. Em vista dos acontecimentos deste momento, essa documentação celebra a conclusão de nossas graduações, além disso, comprova a capacidade e potencial de cada alune do Instituto de Artes e da Uerj como um todo.

Palavras-chaves: Monografias. Artes. História da arte. Educação.

\section{Undergraduate Journal}

Abstract: This journal reunites the abstracts of the undergraduate dissertations presented by IART students in the 2020 academic year. In view of ongoing events of this time, this documentation celebrates the completion of our undergraduate degree, and testifies the capacity and potential of each student of the Institute of Arts and of UERJ as a whole.

Keywords: Undergraduate dissertations. Arts. Art history. Education.

I Universidade do Estado do Rio de Janeiro, São Francisco Xavier, 524 - Maracanã, Rio de Janeiro, R.J, 20943000. E-mail: anaterezapl@hotmail.com ORCID: https://orcid.org/0000-0001-7582-6040 Rio de Janeiro, Brasil.

II Universidade do Estado do Rio de Janeiro, São Francisco Xavier, 524 - Maracanã, Rio de Janeiro, R.J, 20943000. E-mail: lineseixas@yahoo.com.br ORCID: https://orcid.org/0000-0002-2370-1155 Rio de Janeiro, Brasil.

III Universidade do Estado do Rio de Janeiro, São Francisco Xavier, 524 - Maracanã, Rio de Janeiro, R.J, 20943000. E-mail: amandacampos.10@hotmail.com ORCID: https://orcid.org/0000-0001-7822-4889 Rio de Janeiro, Brasil.

IV Universidade do Estado do Rio de Janeiro, São Francisco Xavier, 524 - Maracanã, Rio de Janeiro, R.J, 20943000. E-mail: arfpdomiciano@gmail.com ORCID: https://orcid.org/0000-0003-4594-1245 Rio de Janeiro, Brasil.

V Universidade do Estado do Rio de Janeiro, São Francisco Xavier, 524 - Maracanã, Rio de Janeiro, R.J, 20943000. E-mail: anaclarapschubert@gmail.com ORCID: https://orcid.org/0000-0002-4066-0041 Rio de Janeiro, Brasil.

VI Universidade do Estado do Rio de Janeiro, São Francisco Xavier, 524 - Maracanã, Rio de Janeiro, R.J, 20943000. E-mail: ongakudrummond@gmail.com ORCID: https://orcid.org/0000-0003-0914-5145 Rio de Janeiro, Brasil.

VII Universidade do Estado do Rio de Janeiro, São Francisco Xavier, 524 - Maracanã, Rio de Janeiro, R.J, 20943000. E-mail: iacillobia@gmail.com ORCID: https://orcid.org/0000-0001-8191-782X Rio de Janeiro, Brasil.

VIII Universidade do Estado do Rio de Janeiro, São Francisco Xavier, 524 - Maracanã, Rio de Janeiro, R.J, 20943000. E-mail: bumoraes@hotmail.com ORCID: https://orcid.org/0000-0002-0040-5003 Rio de Janeiro, Brasil.

IX Universidade do Estado do Rio de Janeiro, São Francisco Xavier, 524 - Maracanã, Rio de Janeiro, R.J, 20943000. E-mail: carolinamgfpereira@gmail.com ORCID: https://orcid.org/0000-0002-6886-6447 Rio de Janeiro, Brasil. 
X Universidade do Estado do Rio de Janeiro, São Francisco Xavier, 524 - Maracanã, Rio de Janeiro, R.J, 20943000. E-mail: claramayall@hotmail.com ORCID: https://orcid.org/0000-0003-4157-2366 Rio de Janeiro, Brasil.

XI Universidade do Estado do Rio de Janeiro, São Francisco Xavier, 524 - Maracanã, Rio de Janeiro, R.J, 20943000. E-mail: vicenterocha.fotografia@gmail.com ORCID: https://orcid.org/0000-0001-6225-8187 Rio de Janeiro, Brasil.

XII Universidade do Estado do Rio de Janeiro, São Francisco Xavier, 524 - Maracanã, Rio de Janeiro, R.J, 20943000. E-mail: ericacastello@id.uff.br ORCID: https://orcid.org/0000-0002-2632-0956 Rio de Janeiro, Brasil.

XIII Universidade do Estado do Rio de Janeiro, São Francisco Xavier, 524 - Maracanã, Rio de Janeiro, R.J, 20943000. E-mail: gabib02@gmail.com ORCID: https://orcid.org/0000-0003-2653-7167 Rio de Janeiro, Brasil.

XIV Universidade do Estado do Rio de Janeiro, São Francisco Xavier, 524 - Maracanã, Rio de Janeiro, R.J, 20943000. E-mail: guilhermelemosdeazevedo@gmail.com ORCID: https://orcid.org/0000-0002-8562-1978 Rio de Janeiro, Brasil.

XV Universidade do Estado do Rio de Janeiro, São Francisco Xavier, 524 - Maracanã, Rio de Janeiro, R.J, 20943000. E-mail: isabella.birani@gmail.com ORCID: https://orcid.org/0000-0002-1356-250X Rio de Janeiro, Brasil.

XVI Universidade do Estado do Rio de Janeiro, São Francisco Xavier, 524 - Maracanã, Rio de Janeiro, R.J, 20943000. E-mail: judy_evelyn@hotmail.com ORCID: https://orcid.org/0000-0002-7878-2642 Rio de Janeiro, Brasil.

XVII Universidade do Estado do Rio de Janeiro, São Francisco Xavier, 524 - Maracanã, Rio de Janeiro, R.J, 20943000. E-mail: jpandarian@gmail.com ORCID: https://orcid.org/0000-0002-7427-3277 Rio de Janeiro, Brasil.

XVIII Universidade do Estado do Rio de Janeiro, São Francisco Xavier, 524 - Maracanã, Rio de Janeiro, R.J, 20943000. E-mail: luizarthurribeiro0@gmail.com ORCID: https://orcid.org/0000-0003-1036-496X Rio de Janeiro, Brasil.

XIX Universidade do Estado do Rio de Janeiro, São Francisco Xavier, 524 - Maracanã, Rio de Janeiro, R.J, 20943000. E-mail: marianapegas@gmail.com ORCID: https://orcid.org/0000-0003-0016-4470 Rio de Janeiro, Brasil.

XX Universidade do Estado do Rio de Janeiro, São Francisco Xavier, 524 - Maracanã, Rio de Janeiro, R.J, 20943000. E-mail: mariaclara2828@gmail.com ORCID: https://orcid.org/0000-0003-1035-9597 Rio de Janeiro, Brasil.

XXI Universidade do Estado do Rio de Janeiro, São Francisco Xavier, 524 - Maracanã, Rio de Janeiro, R.J, 20943000. E-mail: mhmotta15@gmail.com ORCID: https://orcid.org/0000-0002-2713-0177 Rio de Janeiro, Brasil.

XXII Universidade do Estado do Rio de Janeiro, São Francisco Xavier, 524 - Maracanã, Rio de Janeiro, R.J, 20943000. E-mail: mspdurand@gmail.com ORCID: https://orcid.org/0000-0003-0998-7932 Rio de Janeiro, Brasil.

XXIII Universidade do Estado do Rio de Janeiro, São Francisco Xavier, 524 - Maracanã, Rio de Janeiro, R.J, 20943000. E-mail: vieiranaima@gmail.com ORCID: https://orcid.org/0000-0003-0847-3606 Rio de Janeiro, Brasil.

XXIV Universidade do Estado do Rio de Janeiro, São Francisco Xavier, 524 - Maracanã, Rio de Janeiro, R.J, 20943000. E-mail: racquelffontenele@gmail.com ORCID: https://orcid.org/0000-0002-8215-1691 Rio de Janeiro, Brasil.

XXV Universidade do Estado do Rio de Janeiro, São Francisco Xavier, 524 - Maracanã, Rio de Janeiro, R.J, 20943000. E-mail: renatal.rodrigues@hotmail.com ORCID: https://orcid.org/0000-0001-6700-9374 Rio de Janeiro, Brasil.

XXVI Universidade do Estado do Rio de Janeiro, São Francisco Xavier, 524 - Maracanã, Rio de Janeiro, R.J, 20943000. E-mail: artistasema@gmail.com ORCID: https://orcid.org/0000-0003-0039-2094 Rio de Janeiro, Brasil.

XXVII Universidade do Estado do Rio de Janeiro, São Francisco Xavier, 524 - Maracanã, Rio de Janeiro, R.J, 20943000. E-mail: sofiaskmma@gmail.com ORCID: https://orcid.org/0000-0003-2600-7094 Rio de Janeiro, Brasil.

XXVIII Universidade do Estado do Rio de Janeiro, São Francisco Xavier, 524 - Maracanã, Rio de Janeiro, R.J, 20943000. E-mail: vickylopes.c@gmail.com ORCID: https://orcid.org/0000-0002-7538-7073 Rio de Janeiro, Brasil. 
É com grande alegria que apresentamos o Caderno de Formação dos alunes do Instituto de Artes da UERJ, formandes de 2020 dos cursos de Bacharelado em História da Arte e Artes Visuais e Licenciatura em Artes Visuais.

O presente caderno traz os resumos das monografias apresentadas pelos alunes formandos, orientados pelos professores do IART, e que tratam de questões relacionadas à produção, distribuição, crítica e ensino da arte. Em suas pesquisas, os alunes se debruçam sobre temas diversos, expressando a pluralidade de narrativas do contemporâneo, apresentando questões referentes às poéticas de artistas, das práticas e linguagens, ao papel da instituição, do museu, da escola, da formação de público, ao lugar da memória, das representações da cultura popular e do urbano, entre outros pontos do rico e complexo repertório da atualidade.

O processo de formação - não somente como graduação, finalização de curso, mas de um constituir-se - é ainda mais desafiador. Estamos no segundo ano de uma pandemia que assola o planeta, sinal de tempos distópicos, sombrios, de crises diversas que assaltam nossos dias. Uma sensação vertiginosa de estar em queda livre invade nossas casas.

Mundo esvaziado, de tantas perdas, vidas e afetos, mundo em chamas, coberto de cinzas, de verdades apagadas, certezas dissolvidas, mundo que desmancha, derrete. Mas, mundo, ainda, de possíveis, de criação e reinvenção. Precisamos manter os pés no chão, voltar à terra, ser-árvore, ser-floresta, ser-animal, resgatar a nossa humanidade, nossa fragilidade e força também, partilhando da convivência entre seres.

Pertencer ao campo da arte, contribuir ao seu debate, pensamento, produção, história e educação, dentro da universidade, pública e gratuita, e também fora dela, nos traz a potência de encontros, do cultivar formas de contato, de inventar formas de relação. É diariamente manter a arte viva.

As conquistas nos movem, são um sopro de vida. O constante e eterno vir a ser - ser-artista, ser-professor, ser-historiador de arte, ser-crítico de arte, ser-educador - nos traz para perto de nossos sonhos, desejos e devires.

Algo de nós ainda não pode ser roubado, o conhecimento e a imaginação.

Resistir, resistir, resistir.

A origem do verbo celebrar vem do latim celebrare, que quer dizer "honrar, fazer solenidade", de celebe, "o que é várias vezes repetido", "digno de honras", o que é digno de atenção, aquilo que é percebido, cuidado, cultivado. 
Então, celebremos, a graduação, a arte, a vida.

Parabéns a todes!

Sigamos.

\author{
Ana Tereza Prado Lopes \\ Coordenadora do Bacharelado em Artes Visuais \\ Professora adjunta do Departamento de Linguagens Artísticas \\ IART/UERJ
}

\title{
Sobre germinar no concreto
}

Esse caderno surgiu de um comentário em aula sobre como seria importante documentar a conquista de nossa turma, um modo de celebrar o término de nossa graduação num momento como o que estamos vivendo, em meio a uma pandemia. Quando tivemos a proposta aceita para apreciação, seguindo o espírito uerjiano, estendemos sua abrangência para o maior número de pessoas possível. Percebemos, ao ler os materiais de nossas colegas, do que verdadeiramente se tratava esse caderno: ele é o atestado de qualidade e diversidade do ensino público, gratuito e de qualidade.

Reunimos aqui os resumos ${ }^{1}$ dos trabalhos apresentados nas monografias de conclusão dos três cursos do Instituto de Artes: Artes Visuais Bacharelado, Licenciatura e História da Arte, apresentados no período letivo do ano de 2020. Em meio a uma das mais desafiadoras situações em toda nossa formação, nos revigoramos e reacendemos uma centelha de esperança ao vermos o tamanho potencial que temos, que nossa universidade tem em si. Nossos últimos meses na universidade, e, portanto, nossas pesquisas, foram forjados em meio à pandemia de Covid-19, sob uma administração pública catastrófica. Esta, porém, não foi a única adversidade que encontramos durante nossa formação. A maioria de nossas colegas são ingressantes dos anos de 2015 e 2016, e, desde então, enfrentamos ano a ano alguns dos momentos de maiores mudanças e solavancos não apenas dentro da Uerj, mas no cenário nacional como um todo. Atravessamos paralisações e greves sucessivas, estivemos sob constante ameaça de pri-

1 Alguns resumos acompanham imagens, selecionadas de acordo com as necessidades e escolhas des alunes, que consideraram necessária ou não a inclusão destas para melhor compreensão de seus textos. 
vatização, passamos por adequações curriculares que visavam compensar os períodos em que estivemos sem aulas que acabaram por dificultar e atribular a integralização de nossos estudos. Fora isso, perdemos amigues e colegas para fatalidades e para atos diretos de violência. E para elas dedicamos também este caderno, e nos lembramos e falamos os seus nomes: nossa querida Valda, o querido Samuel, nossa Matheusa. Durante a pandemia perdemos Edson, técnico do Instituto, além des alunes que perderam avós, mães, pais e companheires, e a eles estendemos nossos sentimentos.

Nossa atitude aqui é também reivindicatória da própria vida, nessa conclusão completamos mais uma etapa. Em meio a mais um momento de desalento, a mais um desafio, dessa vez compartilhado com o mundo, nós resistimos. Talvez como sementes, essas monografias venham a germinar artistas, professoras, professores, historiadoras e historiadores que saibam discernir o sentido para o qual nossos esforços devem ser direcionados. Talvez essa seja uma forma de contornar a não inclusão de nossas monografias na biblioteca da universidade, mas que ainda sim foram escritas com todo rigor e qualidade de que somos capazes de produzir. Esse caderno vem como uma forma de marcar o que, em nosso contexto, é mais que uma graduação, mas um acontecimento. Conseguimos.

Esperamos que a leitura e apreciação dos trabalhos aqui compartilhados façam emergir no peito de todes leitores a mesma esperança e força que nos moveram ao longo de nossa graduação.

As organizadoras,

Isabella e Sofia

\title{
Resumos:
}

O corpo e o tempo em Francesca Woodman: A fotografia como um diário

\author{
Aline Beatriz Seixas de Souza - História da Arte \\ Orientador: Marcelo Campos
}

Em meu trabalho foi analisada a produção da fotógrafa norte-americana Francesca Woodman (1958-1981) a fim de traçar como a artista se utilizou da Fotografia e do conceito de foto-performance como uma forma de narrar a si própria e que refletem sua trajetória artística, pessoal e intelectual. Ao utilizarmos de teóricos e historiadores da imagem e da fotografia, além da análise das imagens em si, pode-se perceber como a artista buscou 
Figura 1

Francesca Woodman, About Being My Model, 1976. Gelatina de prata impressa em papel, 14 × $14 \mathrm{~cm}$. Providence, Rhode Island (EUA). (c) Estate of Francesca Woodman.

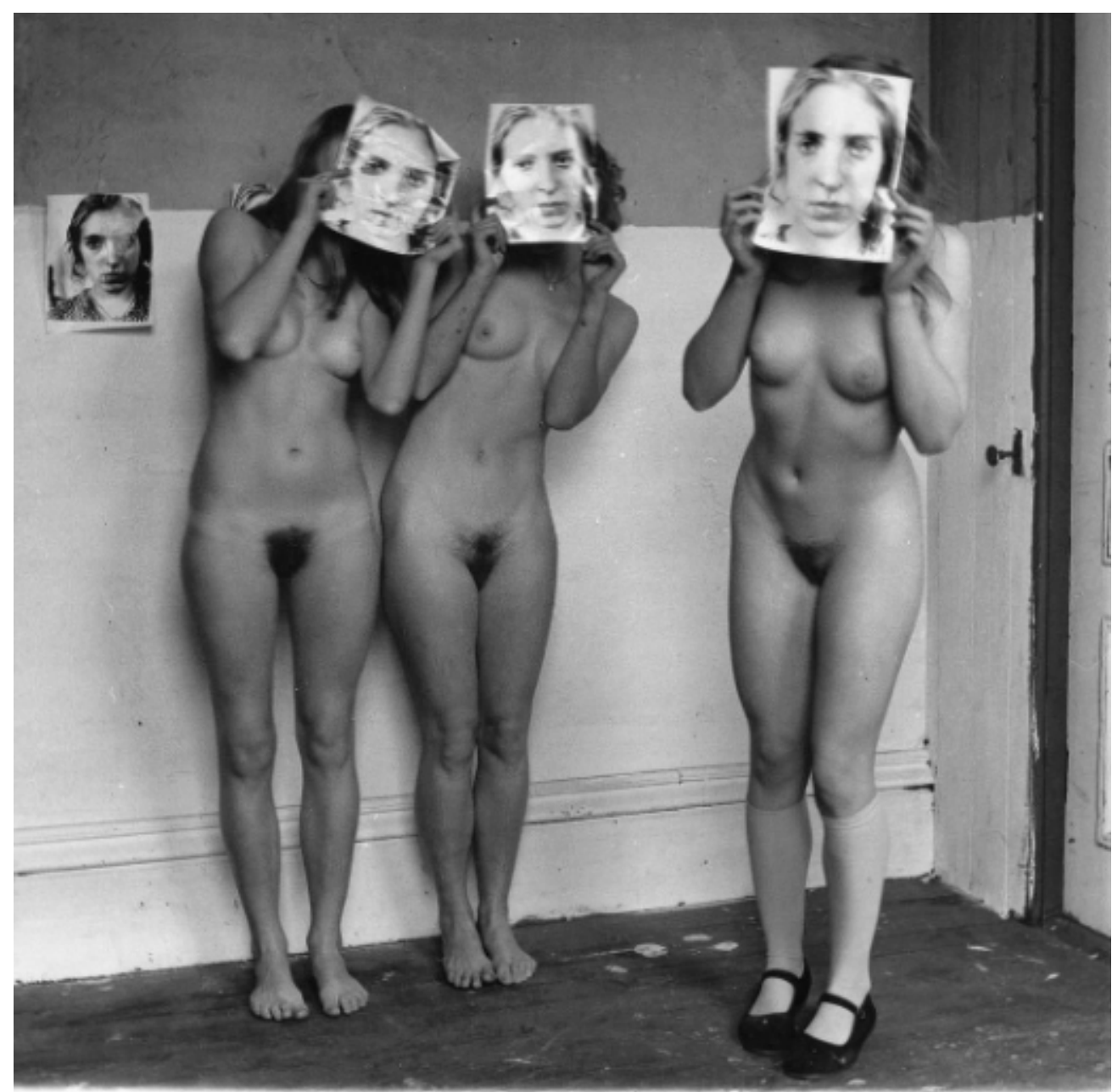

explorar as possibilidades dos processos fotográficos, desde o uso consciente da técnica, como em seus processos de impressão e exposição, e da forma como ocupar a composição fotográfica, com o objetivo de criar uma linguagem e estética próprias, além de utilizar de seu corpo e o de amigos como potência para uma linguagem artística que confronta as relações de identidade e aparência.

\section{O ir e (de)vir: governo de criança}

Amanda Campos Barbosa - Artes Visuais Bacharelado

Orientadora: Maria Moreira de Fátima

Minha pesquisa é sobre tempo, e tem como intuito buscar, analisar, descobrir e entender o que é contar uma história - o que vem a ser o ir e (de) vir quanto ao registro das memórias. Essas que perpassam entre passado, presente e talvez futuro, indo e voltando, tecendo nessa mesma estrutura circular um leque de questões que é o meu tempo, mas afinal, para além 
do meu e do seu, o que é o tempo? Poderia ser a resposta de diferentes experiências, do fazer e do existir, ainda que fragmentado, e de certa forma, incompleto? Como resposta a essa investigação, e dentro desse viver entre tempos o resultado se dá por meio de obras que abordam diferentes momentos do ser.

\section{Localizando Ana Mendieta: diálogos entre o território, o corpo e a falta}

Amanda Rezende de França Pizani Domiciano - História da Arte

Orientadora: Fernanda Pequeno da Silva

Meu trabalho propõe refletir acerca de uma nova narrativa sobre o corpo feminino na arte, a partir do estudo da poética visual da artista cubana Ana Mendieta (1948-1985), durante seu período de formação, compreendendo questões subjetivas apresentadas em seus trabalhos, tais como a terra, o corpo feminino e a ancestralidade. $O$ trabalho é dividido em três capítulos. No primeiro, é traçado um panorama histórico dos Estados Unidos, local em que a artista teve a sua formação artística. No segundo, é desenvolvida a ideia da potência da sua trajetória de vida em sua carreira artística a partir de uma análise das problemáticas em torno do exílio, da identidade e do território. Por fim, investiga-se a série Siluetas (1977), da artista, e sua inquietação com a falta e a tentativa de abordar essa questão em seus trabalhos rituais artísticos.

O mundo acabará em fogo: $O$ incêndio do Museu Nacional e a precarização dos lugares de memória no Brasil

Ana Clara Portela Schubert - Artes Visuais Licenciatura

Orientador: Maurício Barros de Castro

A partir do incêndio que atingiu o Museu Nacional do Rio de Janeiro em setembro de 2018, meu trabalho investiga a simbologia do fogo, principalmente em relação à corrosão dos lugares de memória no Brasil. Na pesquisa, entendendo tal evento como uma tragédia anunciada em vez de um acidente fortuito, constataremos o "caráter ígneo" do descaso generalizado em relação ao setor cultural do país, dada a frequência desse tipo de incidente. A monografia tem como objetivo investigar o que acontece quando objetos de arte e cultura, seja em museus ou outros patrimônios históricos, são atingidos pelo fogo e reduzidos à cinzas. Para contextualizar política e socialmente o incêndio do primeiro museu brasileiro, apresentamos a sua formação e analisamos a grandeza dos danos, contando também com a contribuição de diversos autores para a compreensão das 
noções teóricas de memória e da história do pensamento sobre patrimônio no Brasil.

\section{Crítica e Política sobre a Produção de Arte Nacional Brasileira}

Bárbara Carneiro Drummond Alves - História da Arte

Orientadora: Sheila Cabo Geraldo

Meu trabalho traça uma relação entre a semana de arte moderna de 1922 e a construção da identidade nacional, refletindo nas políticas públicas de financiamento privado de arte.

\section{O desenho animado no cinema}

Beatriz Sampaio lacillo de Albuquerque - Artes Visuais Licenciatura

Orientadora: Ana Valéria de Figueiredo da Costa

Meu trabalho investiga a história do desenho animado ocidental e como esta linguagem entre arte e técnica passou a fazer parte da mídia cinematográfica. É uma pesquisa bibliográfica e está amparada em autores como Alberto Lucena Júnior (2011), Flávia Cesarino Costa (2006) e Henry A. Giroux (2001), relevantes para a discussão sobre o amadurecimento da arte da animação, os primeiros anos de desenvolvimento da mídia cinematográfica e seus reflexos na cultura visual. As considerações finais apontam a importância de interpretar as diversas formas de linguagem, tomando a que leitura de imagem difere do texto verbal, faz parte da alfabetização e letramentos visuais que consideram as experiências culturais/visuais dos estudantes. É desejável que o ensino da arte apresente aos discentes o máximo de experimentações artísticas e, no contexto de seus conteúdos e formas, favorecer diálogos interdisciplinares.

\section{Respiro: entre pedra e concreto ainda se escuta}

Bruna Moraes de Araujo - Artes Visuais Bacharelado

Orientador: Jorgge Menna Barreto

Projeto realizado a partir da investigação do espaço de um terreno baldio, localizado junto a minha atual residência na cidade de São Paulo entre os meses de março de 2020 e maio de 2021: período da pandemia. Mais do que um espaço auto-contido, esse lugar interessa por ser uma fresta no concreto urbano. É nesse intervalo que cultivo, além de plantas, amizades e alimentos, modos de contar as suas histórias, explorando assim as 
Figura 2

Bruna Moraes. Respiro, 2021. Fotografia digital com técnica pinhole, 5 furos sobre o papel. São Paulo.

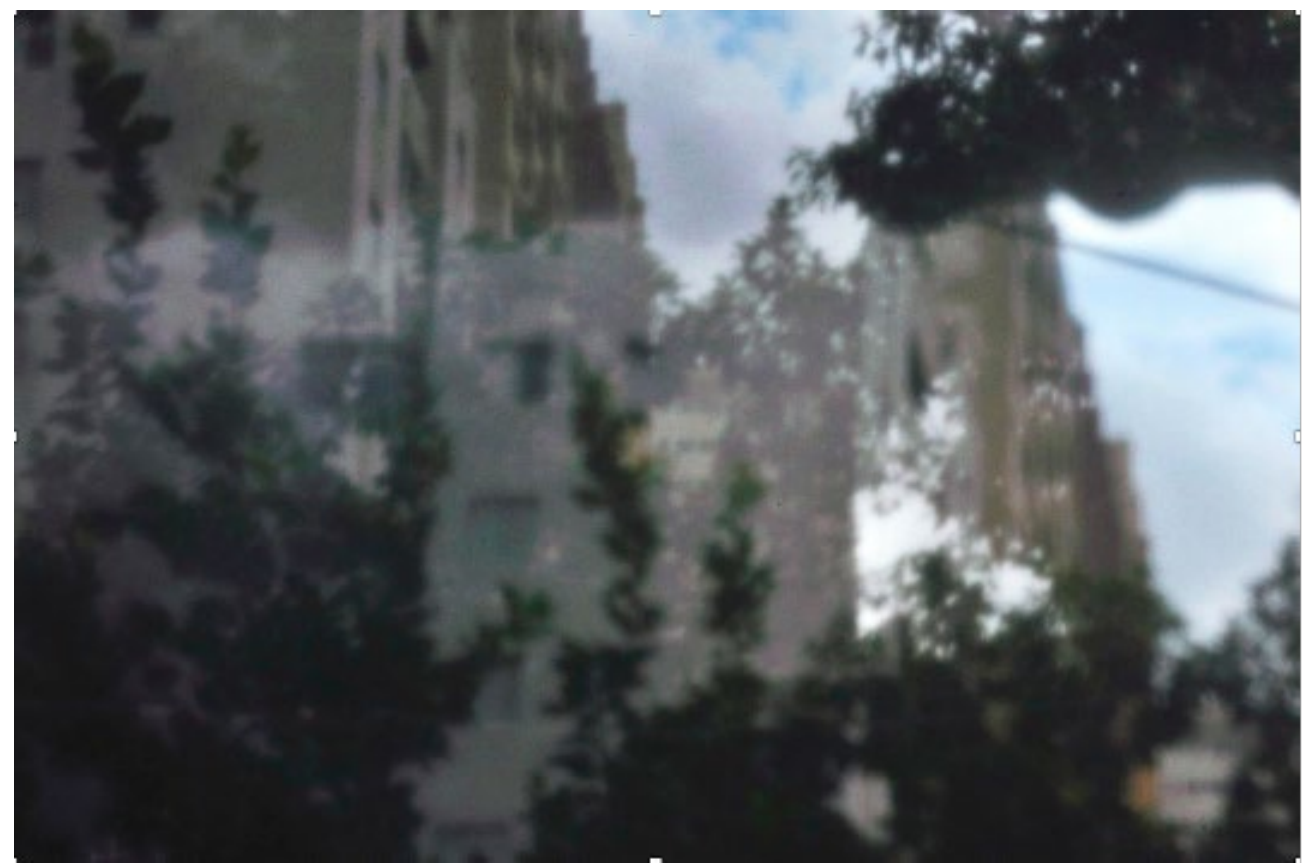

possibilidades e limitações da própria linguagem. A partir de uma escrita múltipla, construo um texto permeável, tecido entre relatos diarísticos e gravuras do local. Visualmente, renuncio à exatidão técnica da fotografia e do vídeo e opto pela técnica pinhole em uma câmera digital para a construção de um filme que compõe com o texto monográfico e as imagens.

\section{A Casa Museu Eva Klabin: as possibilidades de uma educação museal e o público infanto-juvenil}

Carolina Marques Garcia Fernandes Pereira - Artes Visuais Licenciatura

Orientadora: Valéria Leite de Aquino

Meu trabalho teve por objetivo estabelecer relações entre os museus e seus educativos e a educação formal escolar. O que tal relação teria de benéfico para tais alunos em sua formação tanto estudantil quanto cidadã. Para isso, foi utilizado como estudo de caso a escola municipal da cidade do Rio de Janeiro e a Casa Museu Eva Klabin. Para entender como e o porquê de tais relações ocorrerem, buscou-se desenvolver uma breve história das formações dos museus e seus educativos no Brasil e na Europa. Depois, fez-se um paralelo entre a formação do museu específico junto da história de sua criadora, Eva Klabin Rapaport. Fala-se, também, do surgimento do Programa de Educação da Casa Museu e suas atividades com o público espontâneo e o oriundo da escola municipal. Com o entendimento do contexto da pesquisa, elaborou-se as possibilidades que a educação museal da Casa Museu pode oferecer para tais estudantes. 
Figura 3

Clara Mayall. Gertrude, 2021. Técnica mista, $15 \times 20 \mathrm{~cm}$ Rio de Janeiro.

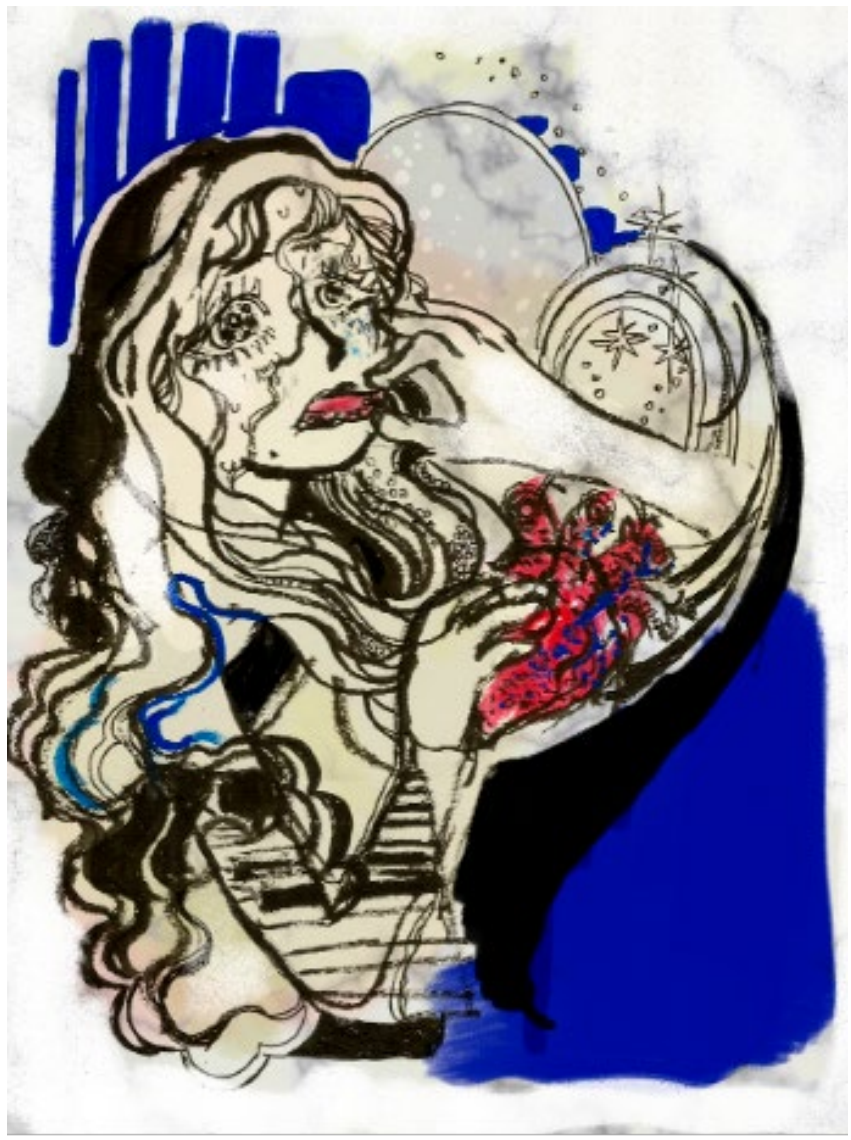

\section{Alguns fatos sobre o coração invisível}

Clara Guaracy Mayall - Artes Visuais Bacharelado

Orientadora: Analu Cunha (Ana Luzia de Lima Cunha)

Trabalho sobre a frustração diante da impossibilidade de, como humanos comuns, rasgar o coração do peito e o vislumbrar; acompanhado da história do coração sagrado, sua iconografia, e algumas das mulheres que o amaram. Monografia feita à mão onde texto e imagem se relacionam visceralmente.

\section{Eu escrevo com tesão}

Ellysson Vicentte Sousa Rocha - Artes Visuais Licenciatura

Orientadora: Renata Gesomino

O trabalho decorrido visa desenvolver um olhar investigativo direcionado a iconografias e iconologias homoeróticas presentes em duas fotografias do artista fotógrafo estadunidense Robert Mapplethorpe. O mesmo foi um dos responsáveis por representar artisticamente a geração underground LGBTQI+ de Nova York dos anos 70 e 80. A pesquisa que tem cunho biográfico e historiográfico e estabelece também uma relação com a pedagogia da 
imagem, ao investigar quatro trabalhos específicos do artista em questão, fragmentando e analisando atravessamentos com signos da cultura visual, e, posteriormente, aplicando os resultados às práticas pedagógicas contemporâneas. A escolha de Snakeman e Cross se deu por meio dos vestígios do vânitas e do homoerotismo vigentes em cada uma das duas obras. Dessa forma, é dissertado o olhar sobre dois tópicos dicotômicos (desejo e fé) usando como bússola as obras do Mapplethorpe.

\section{Cartas de uma educadora: lembretes do passado, perspectivas atuais e vontades futuras}

Érica Castello Castilho - Artes Visuais Licenciatura

Orientador: Aldo Victório Filho

Essas cartas, meu trabalho de final do curso de licenciatura, revelam os anseios futuros de uma educadora em formação contínua sobre seu campo de atuação em artes. Tal escrito é uma prospecção em um modo de operação relacionando experiências passadas e anseios para o futuro. Construindo assim um tratado próprio e ao mesmo tempo teórico sobre arte, educação, política e subjetividade.

\section{Conversas, músicas e danças com meu avô: a Congada como espaço de resistência e arte}

Gabriela Borges de Oliveira Leão - Artes Visuais Bacharelado

Orientadora: Analu Cunha (Ana Luzia de Lima Cunha)

Figura 4

Gabriela Borges. Memórias da Congada, 2020. Frame.

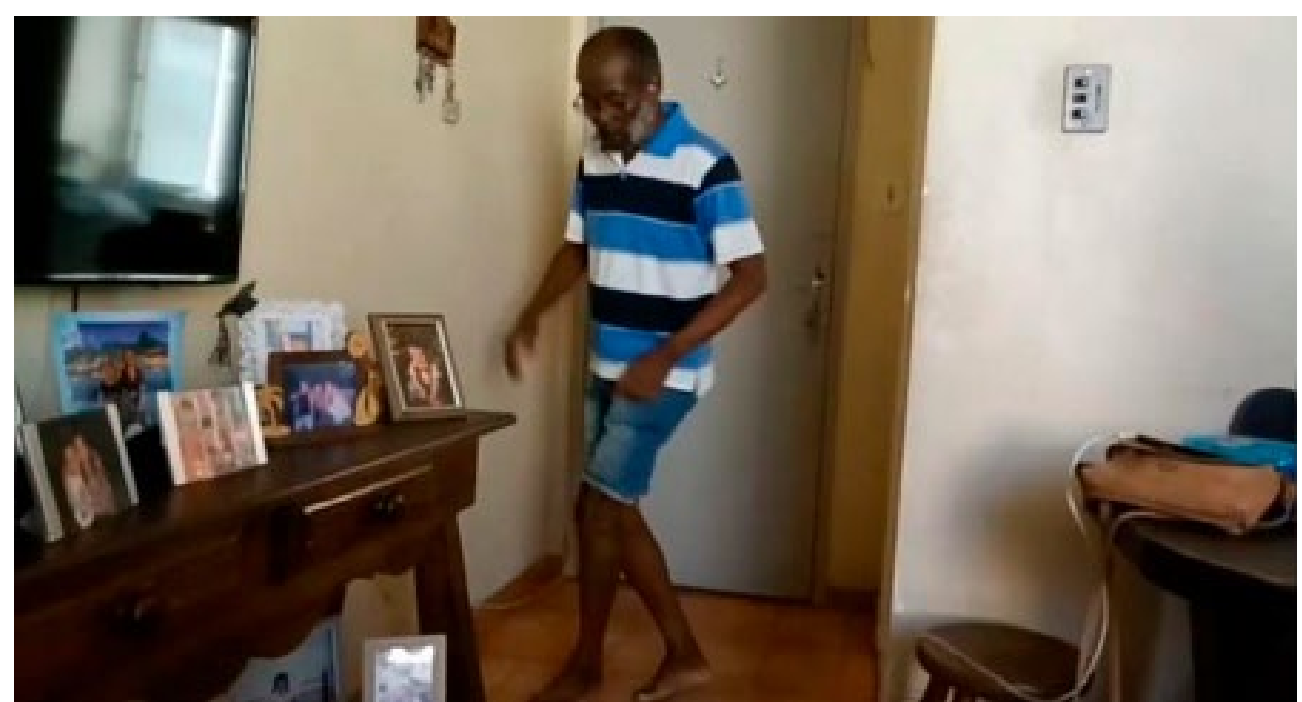


A pesquisa consiste em abordar a Congada, uma manifestação da cultura popular brasileira com influências africanas, através das memórias de Moacir Lopes de Oliveira, herdeiro da Congada na cidade de Rio Casca em Minas Gerais e avô da autora. Um resgate das origens familiares através da relação com o avô e de suas histórias. Uma reflexão sobre a ancestralidade, sincretismo religioso e resistência do povo negro.

\section{Arte, Escola e Educadores: o ensino e quem ensina no meio do caos \\ Guilherme Lemos de Azevedo - Artes Visuais Licenciatura \\ Orientador: Aldo Victório Filho}

Meu trabalho foi realizado querendo observar as maneiras as quais os atores da escola trabalham o ensino de arte e as forças estruturais que o atingiam. Entretanto, as realidades da pandemia pareceram deixar mais escancarada a realidade cruel que atingia os alunos do Ciep 408 Sérgio Cardoso e o Colégio Estadual Lauro Correa, localizados no bairro de Trindade, em São Gonçalo, cidade da região metropolitana do estado do Rio de Janeiro, uma instituição que parece não merecer que ao seu nome seja atribuído uma letra maiúscula. A medida em que as conversas com profissionais dessas instituições se seguem, consegue-se notar as diferenças em abordagem e mentalidade de cada, assim como suas semelhanças em relação ao ensino praticado e estrutura organizacional, demonstrando dois mundos diversos que se parecem, ao mesmo tempo que são completamente diferentes, permeadas por um estado que não parece querer cuidar da educação de seus jovens mais carentes.

\section{Arte Islâmica no Mediterrâneo Medieval: um panorama através de dois artefatos}

Isabella de Oliveira El Birani - História da Arte

Orientadora: Tamara Quírico

O trabalho dedica-se à pesquisa, a partir de dois artefatos em metal - um cantil e uma bacia - feitos na região e período do sultanato Aiúbida (Egito e Síria, séculos XII e XIII), das relações e interconexões da sociedade muçulmana da época com seus contemporâneos no Oriente Próximo e no Mediterrâneo. Baseado em autores que dedicam-se a um estudo aprofundado, mas focado nas especificidades da complexa formação da arte e sociedade muçulmanas, os artefatos são analisados de uma perspectiva ancorada nas particularidades de tal sociedade. Busca-se, além disso, explorar pontos fundamentais da religião islâmica no que tange a sua cultura material e visual, sem homogeneizar, no entanto, a produção e comunidade muçulmana em 
suas muitas diferenças. Por fim, o trabalho tem o objetivo de apresentar os objetos como um panorama para a sociedade e cultura medieval muçulmana, no recorte que vai desde sua formação até meados do século XIII.

\section{Ziguezague: Um percurso pela cidade de Guarapari}

Judy Bonfim Velasquez - Artes Visuais Bacharelado

Orientadora: Maria Luiza Fatorelli

O trabalho consiste em um percurso de investigação artística na cidade de Guarapari - ES, um caminho de coleta de memórias, imagens e percepções. Embasado por reflexões sobre a paisagem vernacular de John Brinckerhoff Jackson e sobre a passagem da noção de percurso entremeado no mundo para a de rua como superfície, experimento no ziguezague uma forma lúdica

Figura 5 Judy Velasquez. Habito o chão, 2021. Vídeo, projeção. Guarapari, Espírito Santo. de habitar a cidade. Busco compreender a dinâmica do vazio/cheio que se estabelece na cidade e que tem relação direta com a conjuntura turística que se impôs ao longo da história de Guarapari. O ziguezague, que se coloca como linha ansiosa, guia o relato e o percurso.

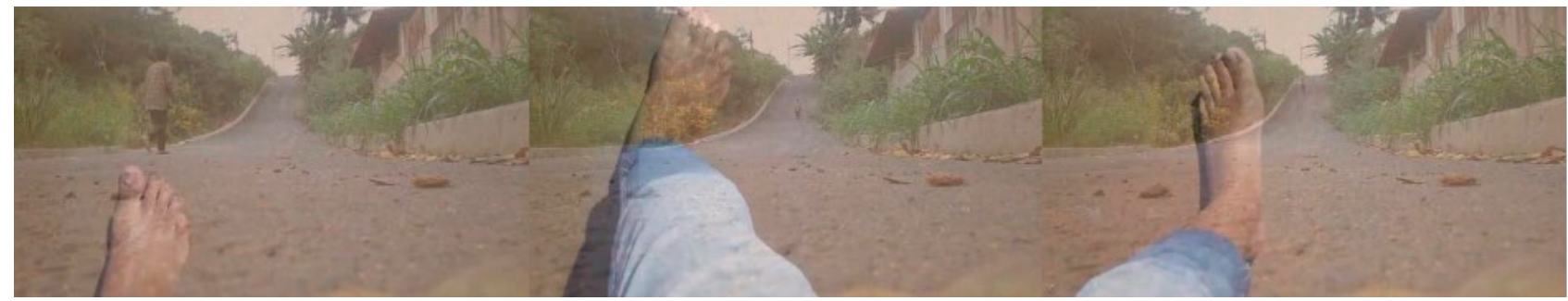

\section{Ma (間) e o Castelo Animado: As manifestações do Ma (間) na anima- ção japonesa}

Julia Barros Nogueira - História da Arte

Orientadora: Marisa Flórido

O projeto visa o desenvolvimento do trabalho que tem como objeto de pesquisa a obra cinematográfica do Studio Ghibli, especificamente, do diretor Hayao Miyazaki, de O Castelo Animado, de 2014. Miyazaki falava sobre a ideia de $\mathrm{Ma}$, presente nas narrativas de seus filmes, um entre-espaço intervalar que é característico da cultura dos japoneses e não está presente nos filmes americanos. São citadas brevemente as primeiras experiências de Miyazaki nas áreas de quadrinhos e animação, como seus papéis em produções pré-Ghibli, para poder ser compreendida a fundação do Studio Ghibli ao lado 
Figura 6 Hayao Miyazaki, cena retirada do filme $O$ Castelo Animado 2004. Produção Studio Ghibli.

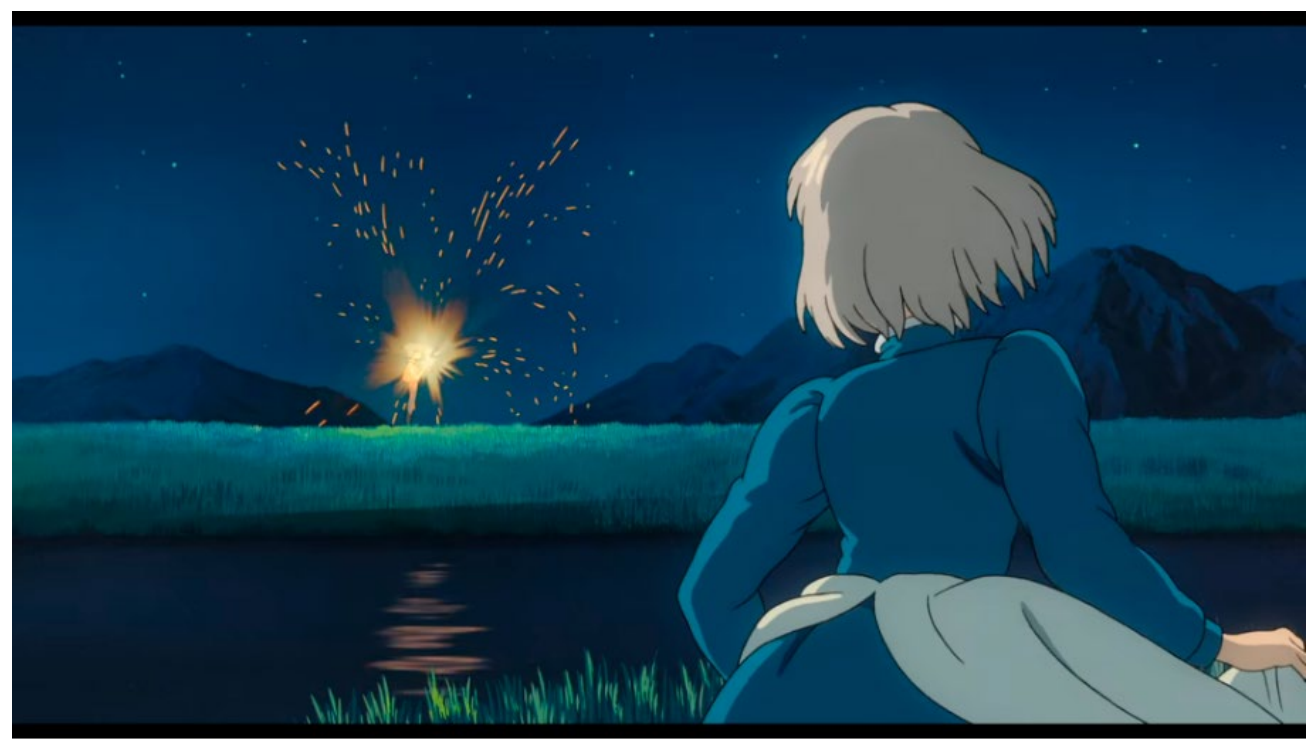

de Isao Takahata. Para me orientar tenho como principal guia o livro MA: Entre-espaço da Arte e Comunicação Japonesa de Michiko Okano, professora de História da Arte da Ásia e do programa de pós-graduação na Unifesp.

\section{Ad Reinhardt e Angelo Agostini: Cartoon e crítica de arte}

Luiz Arthur Bittencourt Ribeiro - História da Arte

Orientadora: Vera Beatriz Siqueira

Através de uma relação anacrônica entre os Salões caricaturais de Ângelo Agostini(1920) e a série How to look At (1947) de Ad Reinhardt, a pesquisa busca encontrar relações entre uma crítica de arte didática, humorística e voltada ao grande público. Evidenciou-se uma semelhança formal da linguagem utilizada pelos dois autores com a linguagem dos memes, muito comum nos últimos anos nos meios virtuais. A partir daí, buscou-se entender como a crítica de arte informal se relaciona midiaticamente, ou com outros artistas, e como o mundo da arte contemporânea se organiza e dialoga com a crítica pelas redes sociais.

\section{Projeto Construção de Memórias: um olhar sobre o campo de interação entre fotografia, educação e saúde mental}

Mariana Pêgas Costa - Artes Visuais Licenciatura

Orientadora: Denise Espírito Santo

O trabalho traz uma interface entre fotografia, educação e saúde mental, como instrumento de reinserção social para pessoas com transtornos 
mentais. Foi realizada uma primeira revisão bibliográfica sobre o tema, incluindo textos médicos, jurídicos e de educação, passando pelo percurso histórico da luta antimanicomial e da reforma psiquiátrica no Brasil, com a implementação de serviços substitutivos ao isolamento e o funcionamento desses serviços no município de Niterói. E ainda, um relato da experiência do projeto de arte-educação Construção de Memórias, realizado pela Sociedade Fluminense de Fotografia (SFF), escola de cursos livres de Fotografia localizada em Niterói, em parceria com o Centro de Convivência e Cultura de Niterói (CCCN), dispositivo público ligado à Coordenação de Saúde Pública da Fundação Municipal de Saúde (FMS).

\section{Experiências sensoriais na sala de aula}

\section{Maria Clara Soares Monteiro de Barros - Artes Visuais Licenciatura}

Orientadora: Isabel Almeida Carneiro

Em "Gravar Ondas" (2018) desenvolve-se uma pesquisa sobre relações sinestésicas entre som e imagem. São apresentados obras e artistas que, intencionalmente ou não, se utilizaram do conceito de sinestesia - interseção entre dois ou mais sentidos. A investigação avança e são analisadas percepções e experiências possíveis com a utilização dos sentidos. Na primeira parte do texto, são expostas obras pessoais e de outros artistas que trabalharam sinestesicamente como Kandinsky, Mondrian, Cildo Meireles e Lygia Pape. Na segunda parte demonstra-se a potencialidade do ensino do desenho para cegos e o da música para surdos, sem a concepção de ideias capacitistas, ressaltando a importância dessas formas de expressão, principalmente a partir dos pensamentos de Batezat e Haguiara-Cervellini. Cita-se ainda algumas metodologias possíveis e são compartilhados os resultados delas. Por fim, são relatadas experiências sensoriais com alunos de um colégio particular do Rio de Janeiro.

\section{Entre caminhos e paisagens: As transformações dos espaços internos e externos através da prática do caminhar}

Maria Helena Paula Motta Gomes - Artes Visuais Bacharelado

Orientador: Alexandre Vogler de Moraes

Através de alguns recursos visuais e um texto literário, cartografei um período que estive em deslocamento. Me interessa pesquisar o âmbito artístico através do ato de caminhar. Em um período de errância, passando por algumas cidades, absorvi camadas de experiência no meu corpo que foram mapeadas através de algumas expressões artísticas. 
Figura 7

Maria Helena Motta,

Série Marieta, 2021.

Stencil em papel pardo,

$0,80 \mathrm{~cm} \mathrm{X} 1,20 \mathrm{~cm} \mathrm{e}$

$0,80 \mathrm{~cm} \times 1,75 \mathrm{~cm}$.

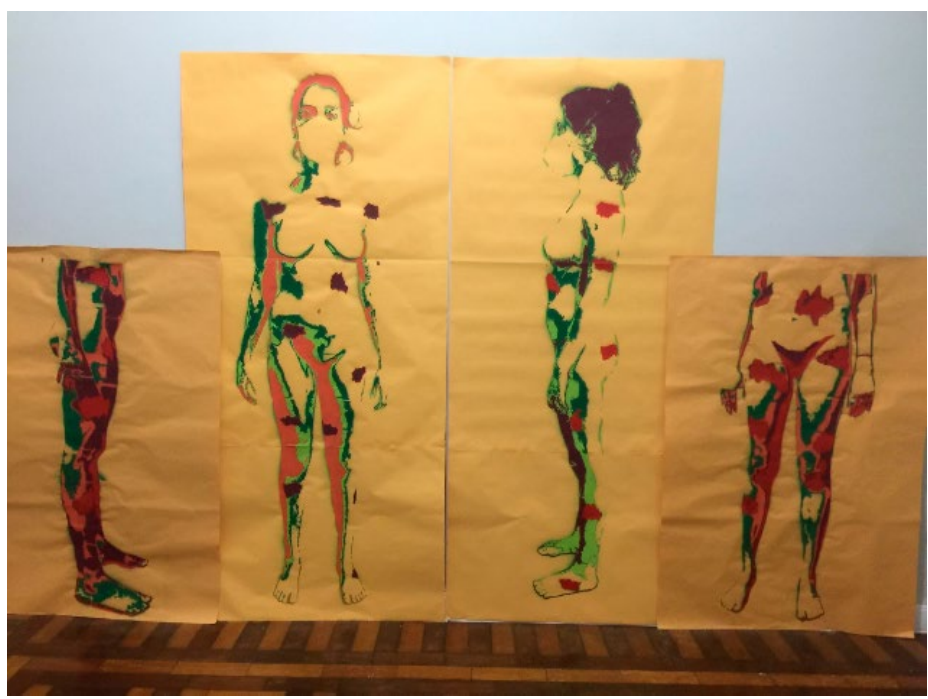

\section{Do olhar à autoimagem}

Monique dos Santos Pereira Durand - Artes Visuais Bacharelado

Orientadora: Maria de Fátima Moreira

O trabalho consiste em uma análise da distorção da autoimagem corporal, provocada por momentos vividos no mundo. A introjeção da pressão estética e da obsessão pelo corpo perfeito é investigada a partir de experimentações em desenhos e áudios, que estruturam e costuram fragmentos de olhares percebidos com o decorrer do tempo. Tais fragmentos são pedaços absorvidos pela mente, que transformam a percepção de como realmente somos e provoca o surgimento de uma imagem deturpada, pautada e alimentada por inseguranças. Confrontá-los abre novas possibilidades de existir.

Figura 8

Monique Durand, Sem Título, 2021. Técnica mista, $15 \mathrm{~cm} \times 21 \mathrm{~cm}$ $\times 2 \mathrm{~cm}$. Rio de Janeiro.

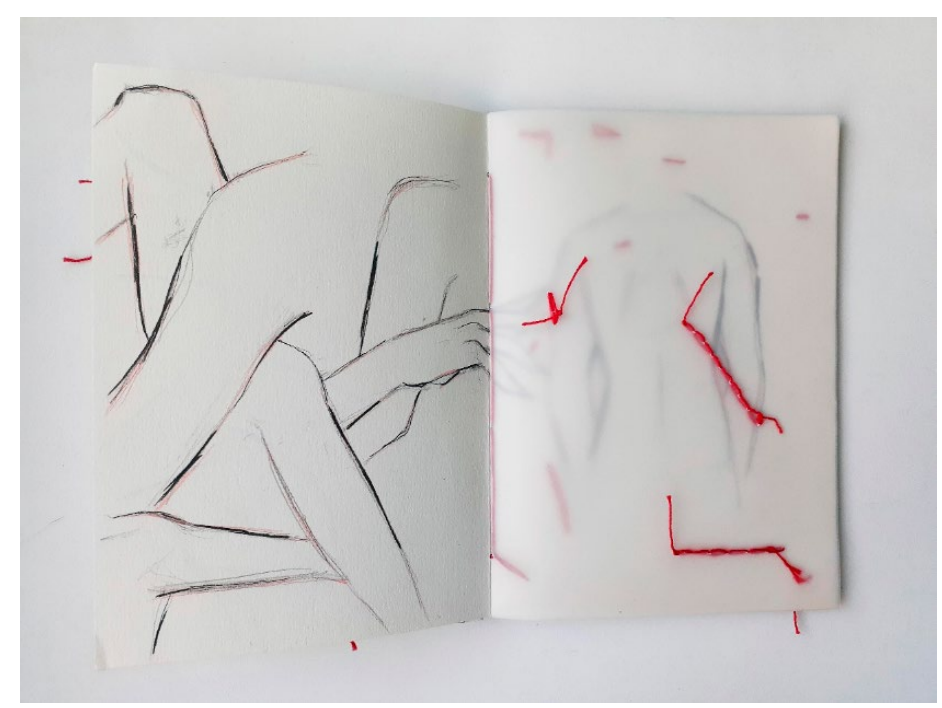




\section{Contribuições de uma flâneur para a formação docente: um passeio pelo imaginário da memória}

Naima Bibas Silva Vieira - Artes Visuais Licenciatura

Orientadora: Ana Valéria de Figueiredo da Costa

O trabalho reafirma a importância do olhar do educador ao habitar a cidade através do flâneur, como um suporte para a compreensão de culturas, vivências, cotidianos e processos artísticos. Relacionando com o conceito da experiência de Jorge Larrosa Bondía, visa contribuir para o entendimento de mundos presentes, passados e futuros. Aprofundamo-nos no universo das fotografias descartadas à venda nos mercados de itens de segunda mão, o Shopping Chão da cidade do Rio de Janeiro. Através da análise de uma coleção pessoal, abriremos espaço para a discussão sobre a valorização da memória e refletiremos sobre as possíveis ressignificações de valor associadas aos registros cotidianos, no âmbito da Arte, através de nosso imaginário da memória. Interessadas na relação entre os temas Cidade e Memória, nos apoiamos na leitura de Walter Benjamin e João do Rio - tendo como referência o livro A alma encantadora das ruas (2007) para elucidar o conceito de flâneur.

\section{O som, a imagem, a mulher, a matriz}

Racquel Crespo Fontenele - Artes Visuais Bacharelado

Orientadora: Inês de Araujo

Figura 9

Racquel Fontenele,

sem título, 2021.

Serigrafia em azulejo

de cerâmica. $54,7 \mathrm{~cm}$

x 54,6 cm. Niterói, Rio de Janeiro.

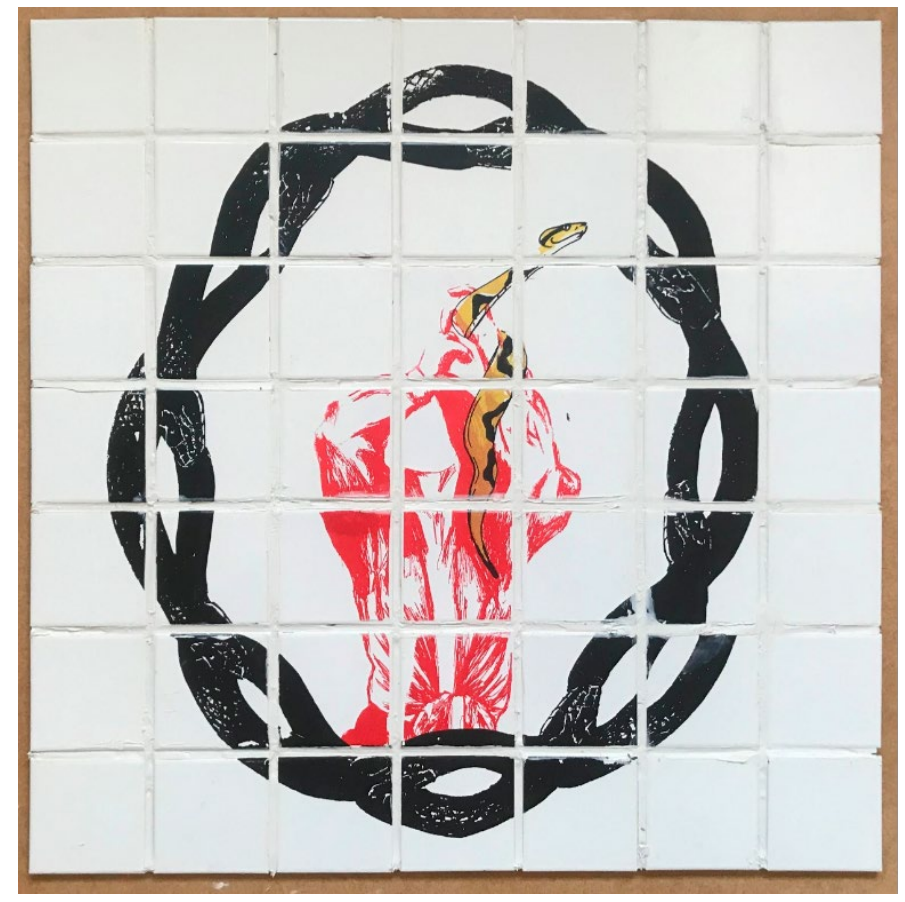


A monografia discorre sobre os caminhos percorridos dentro dos processos de criação para alguns trabalhos artísticos realizados durante a graduação; os rumos intrincados da pesquisa artística; a ironia; o fazer-desfazer do Dadaísmo e a apropriação, bem como questões interpretativas da linguagem do artista em sua produção. São brevemente discutidos conceitos de som e a visualidade de uma linguagem gráfica e sonora. Também são apresentados pontos específicos da serigrafia, expondo possíveis motivos sobre as imagens usadas nas matrizes de silk. $O$ desenvolvimento se dá nas diferentes maneiras encontradas de seguir com as pesquisas durante a graduação, explorando linguagens além da serigrafia.

\section{A gestão de Oswaldo Teixeira e a representação do negro no acervo do MNBA}

Renata Rodrigues - História da Arte

Orientadoras: Evelyne Azevedo (UERJ) e Ana Teles Silva (MNBA)

O processo abolicionista (1888), ao contrário do que se poderia esperar, não desconstruiu os valores associados à cor da pele, mas evidenciou e fortaleceu o processo de discriminação racial já existente no Brasil. Com isso, teorias do "racismo científico" advindas da Europa, ainda que tardiamente, ganhavam cada vez mais espaços entre os intelectuais nacionais, sendo recebidas com entusiasmo, até meados dos anos de 1930.

A pesquisa buscou analisar representações do negro durante os primeiros anos de formação do acervo do Museu Nacional de Belas Artes, que passava pela gestão de Oswaldo Teixeira. Em conjunto com os registros documentais de aquisições do museu, anuários e catálogos de exposições, um grupo de oito obras foi selecionado, como representante de um pensamento vigente defendido, naquele momento, pelo Museu. A partir da análise dessas obras, foi possível compreender melhor como se dava o meio cultural carioca no início do século XX, e as reverberações do discurso difundido pelo MNBA nas décadas posteriores.

\section{VÍDEO, ARTE, QUEER}

Sergio Mauricio Teixeira - Artes Visuais Bacharelado

Orientadora: Analu Cunha (Ana Luzia de Lima Cunha)

O trabalho parte de duas pesquisas desenvolvidas durante minha formação como artista e analisa três obras de minha autoria, resultantes desses processos. A primeira pesquisa se refere à discussão da chamada arte queer e pensa a relação da arte contemporânea com questões de gênero e sexualidade. 
A segunda pesquisa se refere a uma reflexão sobre a videoarte como ferramenta de trabalho e objeto de estudo, além de compreender o seu aspecto social nas relações contemporâneas. Por fim, o trabalho propõe um encontro entre as duas pesquisas e reflete sobre artistas LGBT+ que expressam suas experiências identitárias em obras audiovisuais.

\section{Não sei o que tem aqui dentro}

Sofia S de Souza e Silva - Artes Visuais Bacharelado

Orientadora: Inês de Araujo

Figura 10

Sofia Skmma, sem título (Não Sei), 2021. Serigrafia sobre blocos de papel. Dimensões Variáveis. Rio de Janeiro.

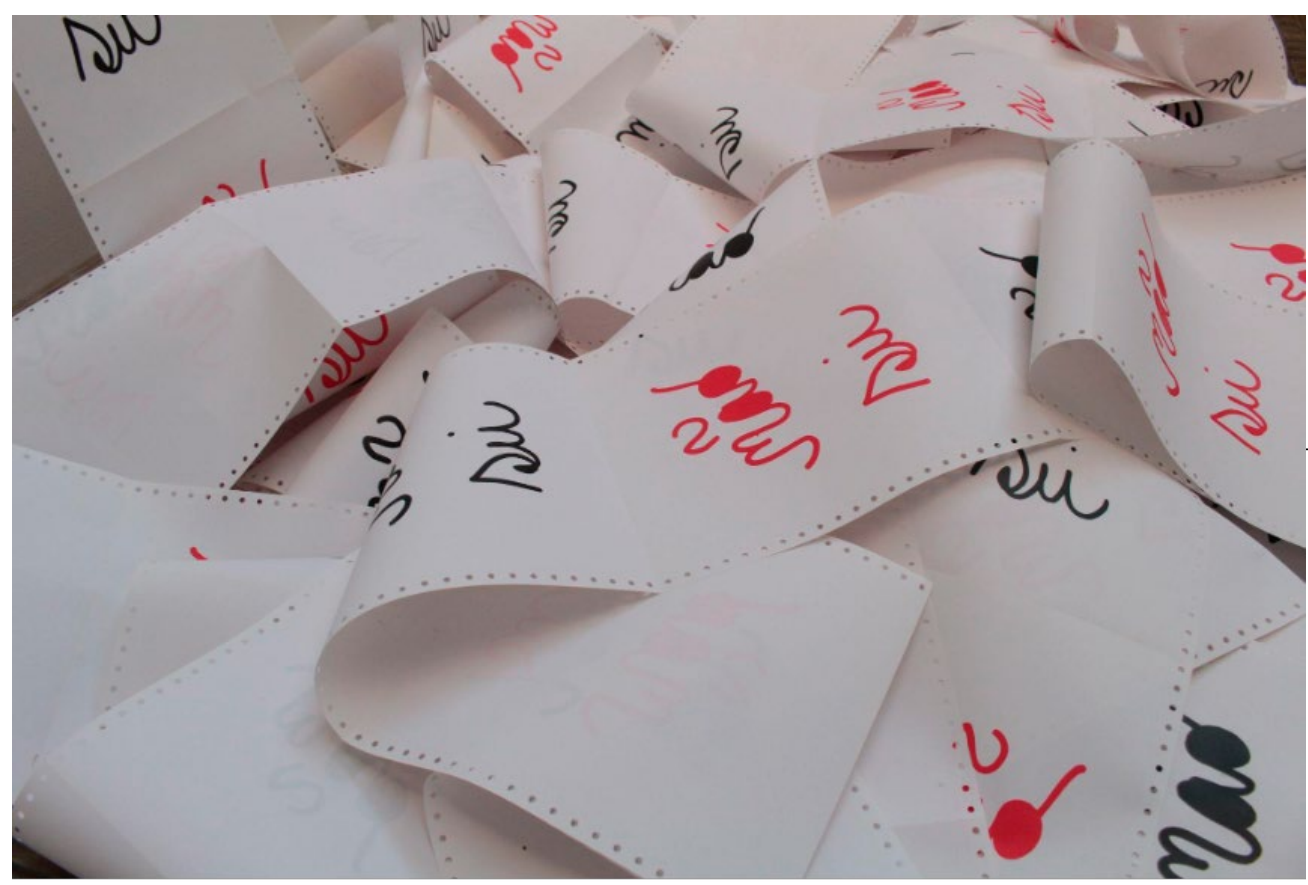

Minha pesquisa de monografia é a apresentação de uma seleção de trabalhos visuais produzidos ao longo do período da graduação que reflete sobre suas construções imagéticas. Propus, ao longo da escrita, articular as produções visuais ao mito de Sísifo, sob o olhar da repetição e do testemunho, questões tratadas em diferentes âmbitos tanto individuais quanto coletivos ao longo das construções visuais. Para isso, procurei criar aproximações entre meus trabalhos e trabalhos escolhidos de algumas artistas contemporâneas de diferentes nacionalidades e períodos como meio de articular reflexões acerca dos problemas suscitados pelas obras, tanto individualmente quanto em relação. Desse modo, minha monografia é predominantemente um trabaIho de análise de imagens com fundamentações teóricas sobre as reflexões advindas das relações propostas. Como conclusão, pretendi levantar a ideia de "Não sei" como fio condutor do processo criativo. 


\section{Passeio: da escola ao museu}

Victória Lopes de Carvalho - Artes Visuais Licenciatura

Orientador: Aldo Victório Filho

O objetivo da pesquisa é, a partir dos passeios escolares, discutir as relações entre os alunos, a escola, os professores e os aparatos culturais. Interessa-nos, portanto, as relações político-culturais dos espaços oficiais de cultura e arte na formação escolar. Compreendendo que a contextualização das artes desempenham papeis decisivos na assimilação dos estudantes, problematizaremos as dificuldades decorrentes das localizações geográficas das escolas e moradias, contextos culturais e seus contrastes e o que influenciam nas necessárias mediações entre as escolas, estudantes e aparato cultural no estado do Rio de Janeiro. O último aspecto que compõe a pesquisa é discutir o panorama de possibilidades das TICs (tecnologias de informação e comunicação), os quais marcam e atravessam a formação do olhar das novas gerações no cenário da Cultura Visual. 